\title{
CORRESPONDÊNCIA
}

\section{CRITÉRIOS DIAGNÓSTICOS DA ESQUISTOSSOMOSE MANSÔNICA MENINGOMIELORRADICULAR}

Muito interessante o artigo de Santos et al. ${ }^{1}$, publicado recentemente neste periódico, abordando o tema "perfil clínico e critérios diagnósticos da mielorradiculopatia esquistossomótica". São escassas as referências na literatura médica a respeito desta neuroparasitose. Acreditamos que a meningo-mielorradiculopatia esquistossomótica seja pouco diagnosticada em nosso meio por falta de critérios diagnósticos bem definidos. Por outro lado, nos últimos anos atendemos quatro pacientes com compressão medular por neoplasias, de localização torácica ou cervical, que tiveram (fora do nosso Serviço) um diagnóstico "definitivo" de mielite esquistossomótica, pelo simples fato do exame do LCR ser reativo em suas provas imunológicas para a esquistossomose mansônica, além do comprometimento medular torácico ou lombossacro. Estes pacientes realizaram avaliação neurorradiológica inadequada (i.e., tomografia computadorizada) ou incompleta (i.e., apenas da medula torácica).

O estudo pela ressonância magnética da medula espinhal em toda sua extensão é imperativo, mesmo porque em dois destes pacientes o nível sensitivo ao exame físico era inicialmente torácico e a neoplasia tinha localização cervical. Este fato já fora levantado previamente por nós², quando, sem a necessidade da realização de uma biópsia medular, elaboramos em 1992 critérios diagnósticos para a neuroesquistossomose (Quadro 1), critérios estes muito semelhantes aos propostos por Santos et al. ${ }^{1}$. Obviamente que com a confirmação da presença de ovos do $S$. mansoni na biópsia medular, o diagnóstico na neuroparasitose seria definitivo e não haveria necessidade de critérios para isto; porém consideramos um procedimento desnecessário, com exceção das formas pseudo-tumorais.

Outro ponto importante é que a mielite esquistossomótica pode envolver a medula cervical. Recentemente, um homem foi operado no HC-UFPE com a suspeita diagnóstica de astrocitoma intramedular cervical, e o achado cirúrgico foi granuloma esquistossomótico. Como estamos em área endêmica da parasitose não é raro o internamento de pacientes, em nossas enfermarias, com a suspeita diagnóstica da neuroparasitose. Até 1994 tínhamos cerca de 60 pacientes, e alguns dos seus aspectos clínicos, cirúrgicos ou neurorradiológicos foram apresentados previamente $^{3-5}$. O quadro clínico neurológico mais frequentemente encontrado nestes pacientes foi mielite (62\%), seguido por mielorradiculite ( $26 \%$ ) e polirradiculite $(6 \%)$. Pleocitose e elevação das proteínas no LCR foram encontradas em $38 \%$ e $56 \%$ dos pacientes, respectivamente. Pleocitose com eosinofilia estava presente em 9\% dos casos. Positividade nas provas imunológicas no LCR foi evidenciada em $74 \%$ dos pacientes, daí preferirmos chamar "acometimento meningo-mielorradicular em pacientes esquistossomóticos" ${ }^{3}$, porque nem todo paciente apresenta positividade nas reações com um único exame do LCR, muitas vezes o exame se positiva semanas após o tratamento da esquistossomose. A presença de ovos do $S$ man- soninas fezes foi encontrada em $37 \%$ dos casos e na biópsia retal em $60 \%$, e a ultra-sonografia hepática mostrava fibrose periportal típica em $100 \%$ dos casos examinados.

Assim, duas condutas essenciais são importantes em um paciente, oriundo de área endêmica, com acometimento meningo-mielorradicular: I. diagnostico da esquistossomose mansônica (clínico, sorológico, parasitológico de fezes, biópsia retal ou ultrassonografia hepática) e II. realização de estudo pela ressonância magnética de toda medula espinhal.

Quadro 1. Critérios diagnósticos da neuroesquistossomose (NE).

\begin{tabular}{ll}
\hline Diagnóstico & Critérios preenchidos* \\
\hline NE "de certeza" & $\mathrm{I}+\mathrm{II}+\mathrm{III}+\mathrm{IV}$ \\
$\mathrm{NE}$ "provável" & $\mathrm{I}+\mathrm{II}$ \\
& ou \\
& $\mathrm{I}+\mathrm{III}$ \\
& ou \\
& $\mathrm{I}+\mathrm{II}+\mathrm{III}$ \\
$\mathrm{NE}$ "possível" & Apenas I
\end{tabular}

*: I, quadro neurológico radiculomedular compatível; com epidemiologia positiva;

II, provas imunológicas (hemaglutinação, IMF ou ELISA) positivas no LCR e/ou soro;

III, a) Presença de ovos de S. mansoni no exame parasitológico de fezes; e/ou

b) biópsia retal compatível com o diagnóstico de esquistossomose mansoni;

IV, avaliação neurorradiológica negativa (exceto nas formas tumorais ou granulomatosas da NE quando o diagnóstico se faz pelo ato cirúrgico)

\section{REFERÊNCIAS}

1. Santos EC, Campos GB, Diniz AC, Leal JC, Rocha MOC. Perfil clínico e critérios diagnósticos da mielorradiculopatia esquistossomótica. Arq Neuropsiquiatr 2001;59:772-777.

2. Valença MM, Barros AC, Ataíde L Jr, et al. Neuroesquistossomose: aspectos epidemiológicos e critérios diagnósticos. Neurobiologia 1992;55:145-152.

3. Valença MM, Barros AC, Borba S, Albuquerque AC, Lima MCM. Acometimento meningo-mielorradicular em pacientes esquistossomóticos: experiência com 50 casos. XVI Congresso Brasileiro de Neurologia, Fortaleza, Brasil. Arq Neuropsiquiatr 1994;52(Supl):O-119 (Resumo).

4. Chagas R, Martinelli VF, Borba SM, Asano N, Valença MM. Dificuldades encontradas no diagnóstico da esquistossomose mansônica em pacientes com neuroesquistossomose. Anais da III Jornada Médica do Hospital Naval de Recife. Recife, 1993: 39 (Resumo).

5. Valença MM, Barros AC, Cunha A, Vieira de Mello R, Lima MCM Schistosomiasis of the spinal cord: surgical, clinical and neuroradiological aspects in 60 cases. Proceedings of the 10th European Congress of Neurosurgery. Berlin: 1995: 169 (Abstract).

Marcelo Moraes Valença Unidade Funcional de Neurologia e Neurocirurgia. Departamento de Neuropsiquiatria Centro de Ciências da Saúde. Universidade Federal de Pernambuco 


\section{Resposta do primeiro autor}

São muito bem-vindas e construtivas as observações de Valença sobre os aspectos acima relatados, demonstrando sua experiência e contribuição com a "meningomielorradiculopatia" esquistossomótica ${ }^{1,2}$.

A neuroesquistossomose pode resultar numa grande variedade de complicações. Seu diagnóstico é difícil, podendo ser confundido com o de outras etiologias ${ }^{3}$. Entretanto, a suspeita clínica da mielorradiculopatia esquistossomótica (MRE) não traz grandes dificuldades, apesar do diagnóstico, na maioria das vezes, ser presuntivo.

O diagnóstico de certeza da MRE repousa na confirmação anatomopatológica, seja por biópsia ou achado post-mortem.

Em sua grande parte, os casos registrados na literatura, bem como os por nós catalogados ${ }^{4}$, receberam este diagnóstico de forma presuntiva. Os critérios usados são suficientes para o estabelecimento de um diagnóstico provável, mas não de certeza.

O objetivo primordial do nosso trabalho é chamar a atenção para a suspeita de mielorradiculopatia esquistossomótica no nosso meio, procurando definir critérios diagnósticos que permitam, de pronto, seu reconhecimento, possibilitando a terapêutica precoce e prevenindo, assim, a evolução para quadros incapacitantes.

Não existe, até o momento, exame complementar que seja patognomônico da MRE. Este diagnóstico se constrói, através de um raciocínio clínico, crítico, sistemático, corroborado por alguns achados laboratoriais.

Com relação ao líquido cefalorraquidiano, não existem elementos bem definidos que possibilitem, através deste método, um diagnóstico definitivo. A síndrome liquórica descrita por Livramento et al. ${ }^{5}$ não é específica para a esquistossomose. As reações imunológicas para esquistossomose não se encontram padronizadas e normatizadas.

A ressonância magnética, sem dúvida, trouxe um grande avanço no reconhecimento e determinação de lesões medulares. Sua realização, quando possível, traz importan- tes informações. Entretanto, apesar de sua alta sensibilidade, sugere possibilidades e não etiologia. Além do mais, a faixa da população que tem acesso a este método é pequena. O custo para estudo de um segmento é alto e a realização em todos os segmentos da medula espinhal, inviabiliza sua utilização corriqueira.

Não pretendemos, hora alguma, deixar de fazer os exames necessários para a constatação do diagnóstico deste envolvimento ou dos possíveis diagnósticos diferenciais. Mas, considerando que vivemos em um país onde as dificuldades propedêuticas são muitas, procuramos salientar a necessidade de se aventar o diagnóstico de MRE em pacientes com quadro clínico compatível. O que não se pode permitir é que, presos a critérios que demandam recursos nem sempre disponíveis, deixemos de pensar nessa possibilidade diagnóstica, e, desta forma, vejamos nossos pacientes fadados a quadros desastrosos.

\section{REFERÊNCIAS}

1. Valença MM, Barros AC, Ataíde L Jr, et al. Neuroesquistossomose: aspectos epidemiológicos e critérios diagnósticos. Neurobiologia 1992;55:145-152.

2. Valença MM, Barros AC, Cunha A, et al. Schistosomiasis of the spinal cord: surgical, clinical and neuroradiological aspects in 60 cases. Proc $10^{\text {th }}$ European Congress of Neurosurgery. Berlin, 1995:169 (Abstract).

3. Haribhai HC, Bhigjel AI, Bill PLA, et al. Spinal cord schistosomiasis. Brain 1991;114:709-726.

4. Santos EC. Perfil diagnóstico da mielorradiculopatia esquistossomótica em três hospitais de Belo Horizonte - Minas Gerai.. Dissertação de Mestrado em Medicina Tropical, Faculdade de Medicina da Universidade Federal de Minas Gerais. Belo Horizonte, 1994.

5. Livramento JA, Machado LR, Caetano da Silva L, Spina-França A. Síndrome do líquido cefalorraquidiano na neuroesquistossomose. Arq Neuropsiquiatr 1985;43:372-377.

Eustáquio Claret dos Santos Rua Domingos Vieira 273/907-10 30150-240 Belo Horizonte MG, Brasil Fax: 3132413418 E-mail:ecsantos@gold.com.br

CORRESPONDÊNCIA. Esta seção de Arquivos de Neuro-Psiquiatria divulga opiniões e observações construtivas acerca de artigos publicados em seus últimos números. São aceitas cartas assinadas, sucintas e desprovidas de caráter pessoal, abordando aspectos objetivos dos artigos e utilizando até cinco referências bibliográficas.

Enviar sua contribuição em uma via acompanhada do respectivo disquete. Utilizar o endereço: Arquivos de Neuro-Psiquiatria Correspondência, Praça Amadeu Amaral 47 / 33, 01327-010 São Paulo SP. 